\title{
Building of A Performance Evaluation Model About Project Management Informatization
}

\author{
Jia Chen \& Xi Deng \\ Institute of Disaster Prevention Xueyuan Street East Yanjiao,Beijing,P.R.China
}

\begin{abstract}
KEYWORD: Project management informatization; BSC; Performance evaluation
ABSTRACT: Building a scientific and reasonable evaluation system for project management informatization has a great effect which is advantageous to assess project management and can indicate the right direction for its construction. This paper, based on the engineering project management implementation cycle, management content, the characteristics of engineering project, and using the theory of BSC, construct a performance evaluation model about engineering project management informatization. In order to provide a new idea for the evaluation research.
\end{abstract}

\section{Introduction}

With the acceleration of economic globalization and informatization, information technology and its application has affected every field and become an important means to enhance the comprehensive ability. At the same time, the state has formulated a series of policies to guide and promote informatization, which enhances enthusiasm of informatization investment. The construction industry as the national pillar industry is no exception.

The informatization development compendium for construction on 2011-2015 and the standards of total contract construction enterprise puts forward requirements and points out the direction for informatization construction. The government and construction enterprises to implement informatization has invested large amounts of funds and resources. How about the effects? The paradox as informatization mire and IT black hole appeared frequently, which seriously affected the confidence of investors and hinder informatization development.Harrington once said:" The evaluation is the key, not evaluation, cannot control; cannot control, cannot

not management, cannot improve." So correct cognition and evaluation performance of informatization can promote rapidly developing and realize maximization value.

\section{Overview of Performance evaluation about project management information}

Informatization is comprehensive using information technology and fully developing information resources. It can improve the efficiency and effectiveness of various departments. As its name suggests, Informatization of project management is that the information technology is applied to the project management business activities in order to improve its performance. Its essence is to take adding value as the target, put advanced management concept as the precursor, and use modern information technology for example computer, network and so on. Project management Informatization is a continuous improvement system engineering. It must be made by the full participation, and covers whole process of the project.

In the field of management, performance refers to the organization and its subsystem performance and business results. Therefore, the informatization performance is the operation process and the operation results of informatization.

The evaluation of project management informationization performance is a judgment which accord certain criteria and certain program to give a fair and accurate evaluation for information work achievement by using some appraisal method. The purpose of evaluation is to improve project management level and enhance the comprehensive competitiveness of the industry by summarizing the experience and lessons of the project management informatization, and finding the weak links ${ }^{[1]}$.

\section{Construct the performance evaluation framework based on the BSC}

Balanced Score Card (BSC) is proposed by Kaplan and Norton (1992). It overcomes the unreasonable evaluation only by some simple financial indicators. It is a strategic method from finance, cus- 
tomer satisfaction, internal processes, learn and growth four different viewpoint to evaluate the val$\mathrm{ue}^{[2]}$, as shown in figure 1. It makes the short-term and long-term goals, financial and nonfinancial indicators, qualitative and quantitative index to get a balance. It is a comprehensive system for measuring enterprise strategy and is an effective method for management.

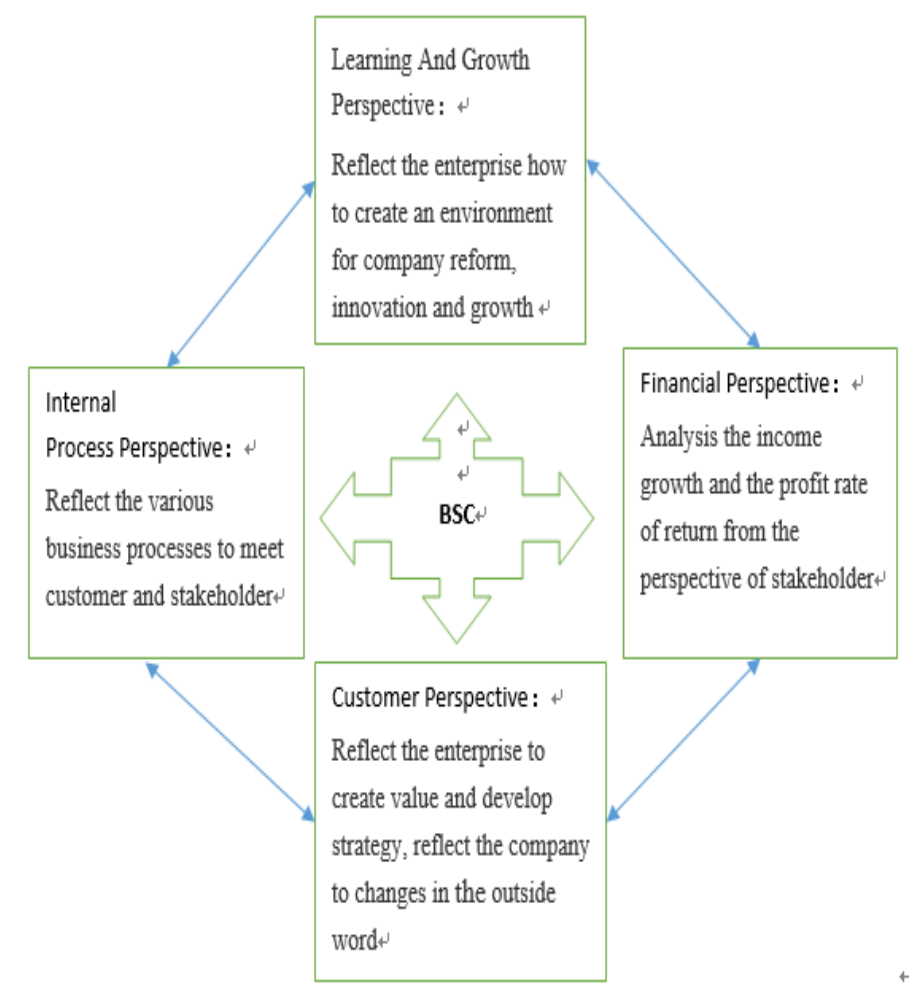

Figure 1. BSC schematic diagram

Because this article discuss the evaluation of project management informatization performance, so it must be turn BSC perspective from the view of measure corporate strategy to the view of measure project management informationization efficiency. The evaluation index system should be simply and accurately reflect the influence of informatization on project management. Therefore, according to the characteristics and objectiveness of project management, this paper turn financial, customer satisfaction, internal process, learning and growth into benefits, related participator, operation, strategic and competitiveness.

\section{Design index system}

Purpose of performance appraisal is to improve the existing situation. If you want to improve, you should have a set of scientific and practical evaluation index. Through the evaluation index, you can be effectively control, supervise and evaluate the process and elements of project information. So the evaluation index system is the key to provide an accurate evaluation. This paper constructs a practical, effective, operable evaluation index system for project management informationization performance through literature search, questionnaire investigation and expert consultation, etc. It combine with the characteristics of engineering project management informatization and project management knowledge system. This index also combined with the national informationization policy, the project management business process, the quality of personnel, related participator, the enterprise information strategic and so on ${ }^{[3]}$. In the process of building, it follow the BSC model and base to the scientific, comparably, operable, oriented, comprehensive principles.

For the four perspective of BSC model, you should pay attention to the relationship between each other. Corporation's ultimate goal is to improve the competition of enterprise strategy. Project severs corporation. So when the informationization of project is analyzed, analysis is the basis of strategic competition. Because the revenue is the end-result of the enterprise, all project informationization evaluation should focus on benefits. This evaluation should emphasis on the operation of informatio- 
nization to ensure interests balance between the relevant participants. The concrete is shown in figure 2 .

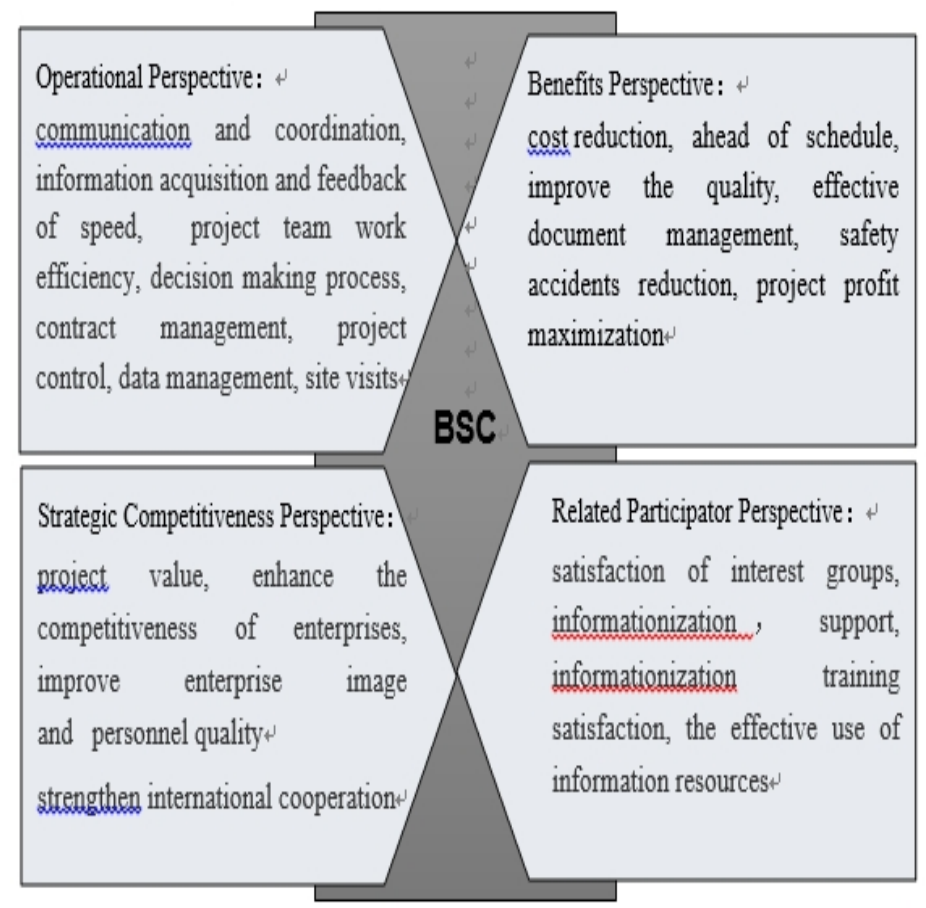

Figure 2. Performance indicators of project management informatization

\section{Operational Perspective}

Operational Perspective instead of the internal process perspective in the BSC model. It mainly reflects the influence of informatization on the management efficiency and effectiveness. This article measure and assess the influence of informationization on the project management process from the following aspects, such as communication and coordination, the speed of information acquisition and feedback, project team work efficiency, decision making process, contract management, project control, data management, site visits and so on.

\section{Benefits Perspective}

Because the process of project have many participants, long implementation cycle and many uncertain factors, which make it more difficult to control. Eventually the project benefits are reduced. So this article mainly from the relationship of informatization implementation and benefits, including tangible and intangible benefits.it mainly consider from cost reduction, ahead of schedule, improve the quality, effective document management, safety accidents reduction and project profit maximization.

\section{Related Participator Perspective}

Project management informationization must be full participation. The project participants include business entrepreneur; construction enterprises, sub-contractor, supervision unit, the government department, survey and design unit, supplier. These units is main part of the implementation of information. In order to evaluate the effect of project management informatization comprehensively, this evaluation system must take into account the interests of the participants. This article has carried on the analysis from the aspects of satisfaction of groups, stakeholders support degree of informatization, satisfaction of training informatization, and the effective use of information resources.

\section{Strategic Competitiveness Perspective}

This angle instead of learning and innovation in BSC model. It is mainly concentrated in how to realize the long-term strategic of enterprise and strengthen enterprise or industry competitiveness 
through the project management informatization. This angle is hard to quantify, but it is an enormous potential for today's information age. We can analyze it through the project value, enhancing enterprise competitiveness, improving the corporate image, improving team personnel quality, enhancing the international cooperation and so on.

\section{Construct a three-dimensional model of performance evaluation}

The performance evaluation of project management informationization can not only detect the actual state and target state gap, but also can timely feedback information to improving the performance and enhance the core competitiveness of enterprises ${ }^{[4]}$. This paper, based on the BSC model and combined with the characteristics of life cycle management, construct a three-dimensional evaluation model for project management informationization.

The first dimension is the performance of project management informatization. It is divided into four grades, such as excellent, nice, good, and poor. It can be concretely make grade according to certain rules. The second dimension is BSC model which includes four aspects of operation, benefits, strategic competiveness, related participator. The third dimension is the process of project management which contain decision, design construction and operation. At different stages related participator has different tasks. The Work of project management informatization are not the same. Therefore, the performance of project management informatization is a dynamic, multifaceted, comprehensive index. The model is shown in Fig .3

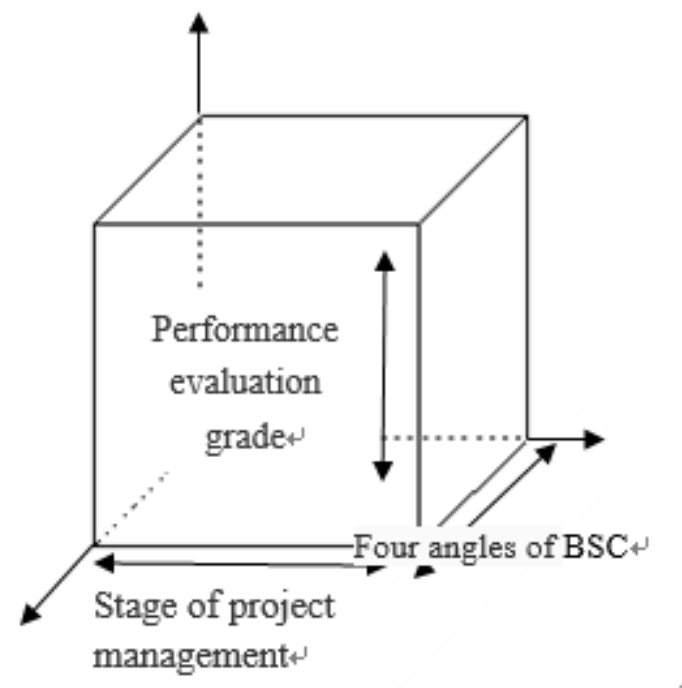

Figure 3. Performance evaluation model

\section{Conclusion}

At present the research about performance evaluation of project management informationization is very few. So, it is very important to establish a reasonable, scientific and applicable model of performance evaluation. This paper through the improvement of 4 dimensions for BSC establishes the evaluation index system of project management informatization performance. It builds a threedimensional evaluation model based on the project life cycle theory. It provides a new idea for the performance evaluation of construction project Informationization.

\section{Acknowledgements}

This work was financially supported by the fundamental research funds for the Central Universities funded for the young teachers (ZY20140209). 


\section{References}

[1] Guangling Zhou. Discussion on Balanced Scorecard Applied to Improve Performance Evaluation of Information [J]. Coal Economic Research, 2012, 3: 62-65(in Chinese).

[2] Lei Cheng. Target System of Performance Evaluation of Engineering Project Management [J].The China Enterprise Operation Research, 2011, 4(1):394-398(in Chinese).

[3] Andrew Brown, John Adams. Measuring the effect of project management on construction outputs: a new approach. International Journal of Project Management, 2000, (18):327-335.

[4] Tong Zhang. The Model and the Performance Estimation Index Used for Management Information System [J]. Manufacture Information Engineering of China, 2005, 12:27-30(in Chinese). 